\title{
Esophageal leiomyomatosis - an unusual cause of pseudoachalasia
}

\author{
Sukanta Ray MS MCh ${ }^{1}$, Sundeep Singh Saluja MS MCh ${ }^{1}$, \\ Ruchika Gupta MD², Tushar Kanti Chattopadhyay MS ${ }^{1}$
}

S Ray, SS Saluja, R Gupta, TK Chattopadhyay. Esophageal leiomyomatosis - an unusual cause of pseudoachalasia. Can J Gastroenterol 2008;22(2):187-189.

Esophageal leiomyomatosis is a rare hamartomatous disorder with varied presentation. In the literature, it is described mostly in children, and is associated with Alport's syndrome. A case of leiomyomatosis that presented as achalasia not associated with Alport's syndrome is described in a 35-year-old woman with a 16-year history of dysphagia. Barium swallow showed a smooth narrowing at the lower end of the esophagus with a longer than usual stricture length. Endoscopy showed a dilated esophagus with a submucosal nodule in the region of the cardia. A computed tomography scan revealed circumferential thickening of the esophagus involving the gastroesophageal junction, with fat planes maintained with the adjacent structure. Endoscopic ultrasound demonstrated a lesion arising from the muscularis propria. The manometry findings were suggestive of achalasia. She underwent transhiatal esophagectomy with gastric pull-up.

Leiomyomatosis should be considered as a cause of psuedoachalasia in patients with symptoms suggestive of achalasia and atypical barium findings. Attempts should be made to confirm the diagnosis preoperatively using computed tomography and/or endoscopic ultrasound. Esophagectomy is the treatment of choice.

\section{Une léiomyomatose œsophagienne : Une cause inhabituelle de pseudoachalasie}

\begin{abstract}
La léiomyomatose œsophagienne est un trouble hamartomateux rare dont la présentation est variée. Dans les publications, on la décrit surtout chez les enfants, et elle s'associe au syndrome d'Alport. Un cas de léiomyomatose prenant la forme d'une achalasie non associée au syndrome d'Alport est décrit chez une femme de 35 ans souffrant de dysphagie depuis 16 ans. Le repas baryté a révélé un rétrécissement régulier à l'extrémité inférieure de l'œsophage, plus long qu'à l'habitude. L'endoscopie a démontré un œsophage dilaté avec nodule sous-muqueux dans la région du cardia. Une tomodensitométrie a révélé un épaississement circonférentiel de l'œsophage à la jonction gastro-œsophagienne, les plans adipeux étant maintenus avec la structure adjacente. Leéchoendoscopie a révélé une lésion provenant de la couche longitudinale. Les résultats de la manométrie étaient indicateurs d'une achalasie. La patiente a subi une œesophagectomie transhiatale avec rétablissement gastrique.

La léiomyomatose devrait être considérée comme une cause de pseudoachalasie chez les patients présentant des symptômes indicateurs d'une achalasie et dont les résultats du repas baryté sont atypiques. Il faudrait tenter de confirmer le diagnostic avant l'opération par tomodensitométrie ou échoendoscopie. L'œsophagectomie est le traitement de choix.
\end{abstract}

Key Words: Dysphagia; Esophagus; Leiomyomatosis; Pseudoachalasia

C sophageal leiomyomatosis is a rare hamartomatous disorder. EIt was first described by Hall in 1916 (1) as a diffuse proliferation of esophageal smooth muscle. This condition predominantly affects children and young adults, but can present at any age. It may occur in isolation or in association with Alport's syndrome and visceral leiomyomatosis (2-5). We report a case of a 35-year-old woman with diffuse esophageal leiomyomatosis who presented with features suggestive of achalasia cardia.

\section{CASE PRESENTATION}

A 35-year-old woman presented with a 16-year history of slowly progressive dysphagia. It was not associated with significant weight loss or anorexia. She experienced frequent episodes of regurgitation and soiling of pillows at night. During the last six months, she had multiple episodes of bronchospasm and was treated with bronchodilator, with partial relief. She was evaluated in a private hospital by barium swallow of the esophagus, which was suggestive of achalasia cardia. She was then referred to the All India Institute of Medical Sciences (Ansari Nagar, New Delhi, India) for definitive management. She had undergone left thoracotomy for similar symptoms 16 years previously (no operative detail was available) and was asymptomatic for six years following the operation. Her physical examination was unremarkable. The biochemical and hematological investigations were within normal limits.

The barium swallow (Figure 1A) showed a dilated cervical and thoracic esophagus with a smooth narrowing at the level of the gastroesophageal junction, along with proximal hold-up of contrast. On fluoroscopy, no peristalsis was seen in the dilated esophagus and there was infrequent relaxation of the gastroesophageal junction. Upper gastrointestinal endoscopy revealed a dilated esophagus with a small submucosal nodule in the cardia. A computed tomography (CT) scan of the chest and upper abdomen (Figure 1B) showed circumferential wall thickening (greater than $1 \mathrm{~cm}$ ) in the region of the gastroesophageal junction, with a proximally dilated esophagus. Periesophageal fat planes were preserved. There was no focal

${ }^{1}$ Department of Gastrointestinal Surgery; ${ }^{2}$ Department of Pathology, All India Institute of Medical Sciences, Ansari Nagar, New Delhi, India.

Correspondence: Dr Sundeep Singh Saluja, Room 1005, PC block, 1st floor, Department of Gastrointestinal Surgery, All India Institute

of Medical Sciences, Ansari Nagar, New Delhi 110029, India. Telephone 91-112-658-8700, fax 91-112-658-8663,

e-mail sundeepsaluja@yahoo.co.in

Received for publication June 9, 2007. Accepted June 28, 2007 


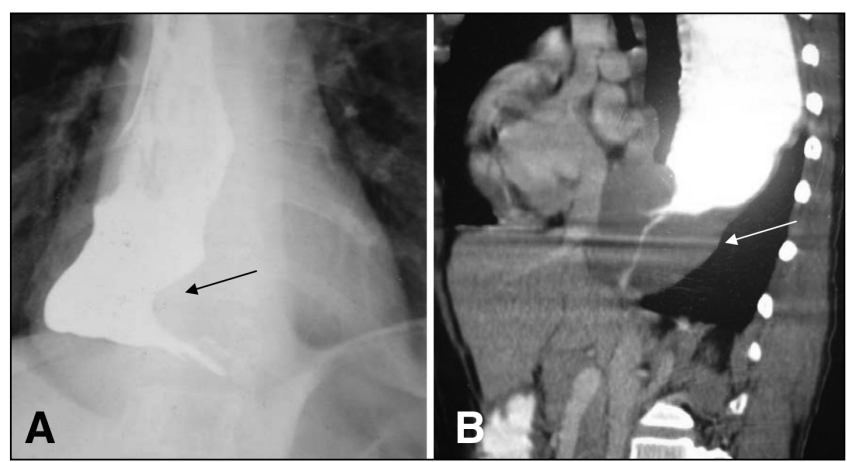

Figure 1) A Barium swallow study, showing a dilated esophagus with a smooth narrowing (arrow) at the gastroesophageal junction. B Computed tomography scan, showing a circumferential wall thickening (arrow) in the region of the gastroesophageal junction with a proximal dilated esophagus

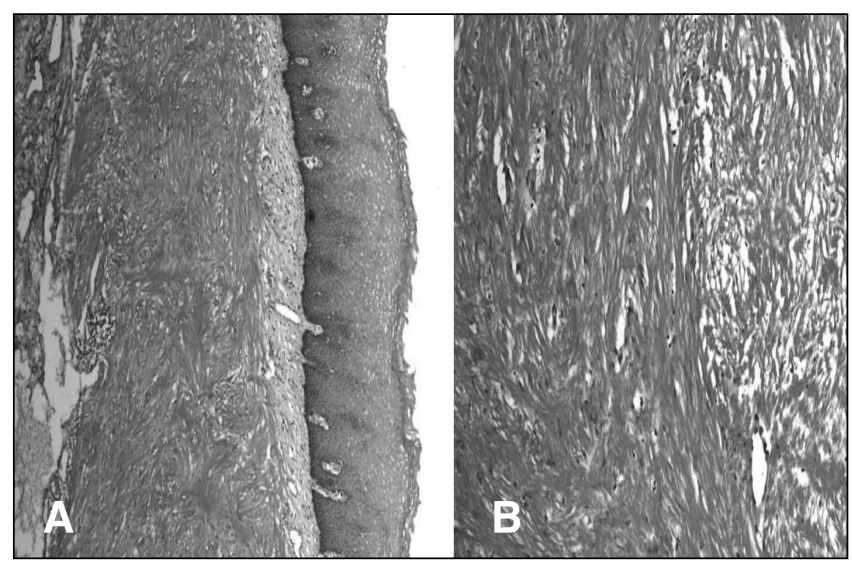

Figure 2) A Microphotograph, showing esophageal mucosa on the right with an unencapsulated spindle cell lesion in the submucosa (hematoxylin and eosin stain, original magnification $\times 40$ ). B Higherpower microphotograph, demonstrating intersecting fascicles of spindle cells possessing eosinophilic cytoplasm and normochromatic elongated nuclei. Note the absence of pleomorphism, mitotic activity or necrosis (hematoxylin and eosin stain, original magnificaion $\times 200$ )

lesion seen in the liver. An endoscopic ultrasound (EUS) showed concentric thickening of the muscularis propria of the esophagus, from $30 \mathrm{~cm}$ to $40 \mathrm{~cm}$. Esophageal manometry showed simultaneous, multiple, low-amplitude contractions with increased intraesophageal pressure. Lower esophageal sphincter pressure was elevated $(39.9 \mathrm{mmHg})$.

She was scheduled for an esophagectomy with a working diagnosis of pseudoachalasia. A transhiatal esophagectomy with gastric pull-up and cervical esophagogastrostomy (side-toside stapled anastomosis was performed, using an EZ45 endoscopic linear cutter [Ethicon Inc, USA]). The postoperative course was uneventful. A Gastrografin (Schering AG, Germany) study performed on the sixth postoperative day showed no anastomotic leakage or hold-up of contrast. The patient resumed oral intake on the same day. After three years of follow-up, she was asymptomatic.

The resected specimen showed a grossly thickened esophagus extending up to the cervical esophagus, approximately $3 \mathrm{~cm}$ below the proximal resected margin. On the cut section, a fleshy, whorled mass $(10 \mathrm{~cm} \times 15 \mathrm{~cm})$ was seen in the lower

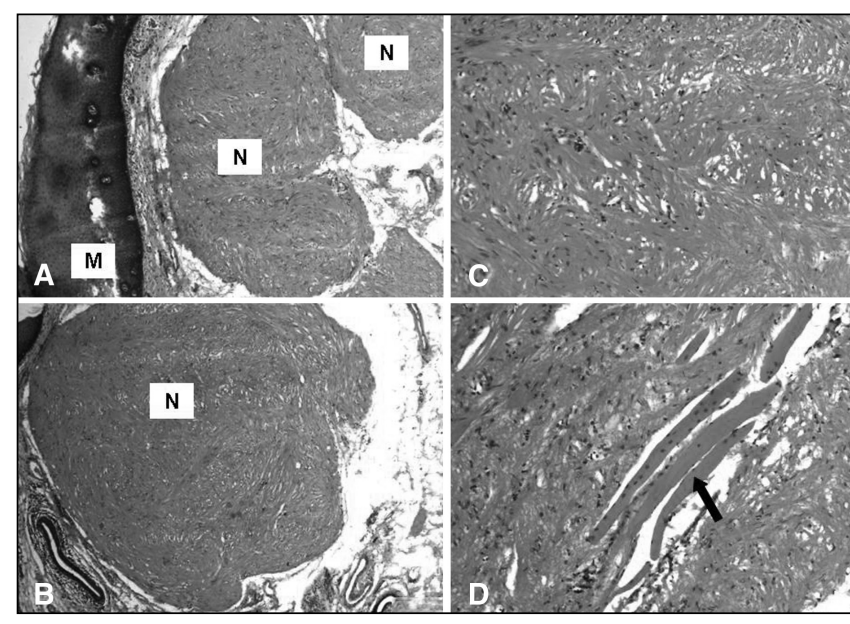

Figure 3) Photomicrographs from the esophagectomy specimen, showing leiomyomatous nodules (N) beneath the mucosa (M) (A and B); a higher-power view, showing spindle cells with eosinophilic cytoplasm and elongated nuclei $(\mathbf{C})$; and diffuse infiltration of the leiomyomatous proliferation between the normal muscle fibres (arrow in D)

one-third of the esophagus. The overlying mucosa was normal. Microscopic examination revealed a diffusely thickened muscular coat of the esophagus, with more pronounced hypertrophy at the gastroesophageal junction. Multiple sections from the thickened wall showed features compatible with diffuse leiomyomatosis (Figure 2). There was no hypercellularity, necrosis or significant mitotic activity. The proximal resected margin also showed diffuse hypertrophy of smooth muscle. In addition, there were discrete submucosal nodules composed of spindle cells with elongated, blunt-ended nuclei suggestive of small leiomyomas associated with diffuse leiomyomatosis (Figure 3). The diffuse proliferation of smooth muscle cells was also seen to infiltrate between the normal skeletal muscle bundles, especially in the upper and middle part of the esophagus (Figure 3).

\section{DISCUSSION}

Esophageal leiomyomatosis is a rare clinical entity. It is characterized by a proliferation of smooth muscle cells in the esophageal wall, causing circumferential thickening. It must be distinguished from leiomyoma, which is a focal, encapsulated lesion and a true neoplasm. Both processes can, however, occur simultaneously in the same patient (6). In addition, it should be differentiated from diffuse circumferential thickening of the esophageal musculature that may occur in neuromotor functional disorders (7).

Although it can occur at any age, it is more common in children and young adults, and is 1.6 times more common in women. In pediatric patients, the usual age at presentation is between 10 and 14 years (5). The youngest reported patient was six months of age (2).

Patients develop symptoms because of encroachment of the lumen of the esophagus by thickened and hypertrophied musculature. The most common presentation is dysphagia for a long duration. Other symptoms include regurgitation, dyspepsia, cough, dyspnea and weight loss. Our patient presented with the typical features of achalasia, with symptoms lasting for 16 years.

Because of its rarity, the preoperative diagnosis is usually difficult. Chest $\mathrm{x}$-ray, barium swallow, endoscopy, CT scan, 
magnetic resonance imaging and EUS are commonly used diagnostic modalities. A chest $\mathrm{x}$-ray may show a mediastinal mass or widening of the mediastinum. A barium swallow study may reveal dilation of the upper esophagus and smooth tapering of the distal esophagus with reduced motility, which may lead to a misdiagnosis of achalasia (5). The stricture length may be longer than that seen in cases of achalasia, as seen in our case. In addition, there may be a smooth eccentric bulge suggesting a submucosal lesion, which helps in differentiating it from achalasia (8).

CT and magnetic resonance imaging are useful to distinguish pseudoachalasia from achalasia. These tests show extension of the soft tissue mass produced by the esophageal wall thickening into the cardia of the stomach, a feature that is not seen with achalasia and is considered to be characteristic of esophageal leiomyomatosis. It also delineates the extent of involvement in leiomyomatosis $(9,10)$.

Endoscopy typically reveals normal mucosa, but esophagitis and esophageal ulceration may be found in some patients (2). EUS is a valuable tool for suspected cases of leiomyomatosis $(5,7)$. It delineates five layers and pinpoints the layer from which the lesion arises. In leiomyomatosis, the thickening arises from the muscularis propria with or without discrete submucosal lesions, as seen in our case. Some investigators believe that EUS is the imaging modality of choice to differentiate achalasia from leiomyomatosis when an initial investigation shows a smooth, tapered narrowing of the distal esophagus (5).

Management depends on clinical symptoms. For asymptomatic patients, who comprise only $5 \%$ of all reported cases, clinical and endoscopic follow-up is satisfactory. Patients with severe and progressive dysphagia should undergo total esophagectomy; this has been performed in $91 \%$ of reported cases. Myomectomy is rarely done, because the results are not satisfactory (5). Both the stomach and colon can be used as a conduit after esophagectomy. When available, it is preferable to use the stomach. It is technically easier to perform, requires a single anastomosis and the stomach has predictable vascularity. In our case, we used the stomach as a conduit, with a favourable outcome. Hirschl et al (11) have shown promising results with gastric transposition for esophageal replacement. Postoperative follow-up is essential to ensure adequate feeding, growth and development, particularly in children. Long-term surveillance is necessary for recurrence of the disease.

\section{REFERENCES}

1. Hall A. A case of diffuse fibromyoma of the esophagus, causing dysphagia and death. Q J Med 1916;9:409-28.

2. Federici S, Ceccarelli PL, Bernardi F, et al. Esophageal leiomyomatosis in children: Report of a case and review of the literature. Eur J Pediatr Surg 1998;8:358-63.

3. Bourque MD, Spigland N, Bensoussan AL, et al. Esophageal leiomyoma in children: Two case reports and review of the literature. J Pediatr Surg 1989;24:1103-7.

4. Lonsdale RN, Roberts PF, Vaughan R, Thiru S. Familial oesophageal leiomyomatosis and nephropathy. Histopathology 1992;20:127-33.

5. Calabrese C, Fabbri A, Fusaroli P, Di Gaetano P, Miglioli M, Di Febo G. Diffuse esophageal leiomyomatosis: Case report and review. Gastrointest Endosc 2002;55:590-3.

6. Lee LS, Nance M, Kaiser LR, Kucharczuk JC. Familial massive leiomyoma with esophageal leiomyomatosis: An unusual
On pathological examination, leiomyomatosis appears as diffuse thickening of the esophagus, which may reach up to $4 \mathrm{~cm}$ in thickness $(2,4,7)$. Leiomyomatosis predominantly affects the middle and distal one-third of the esophagus. It may extend into the cardia and fundus of the stomach in approximately $80 \%$ of cases, whereas the entire esophagus is involved in only $35 \%$ of cases. Microscopic examination reveals predominant hypertrophy of the inner circular layer of the muscularis propria, with lesser involvement of the outer longitudinal layer and muscularis mucosae. Leiomyomatosis displays many features of leiomyoma, such as hypocellular lesions composed of interlacing whorls of smooth muscle cells without evidence of mitotic figures, cellular atypia or vascular invasion $(2,7)$. Calcification and patchy areas of inflammatory cell infiltrates may be found in some cases. Both may be present together. Pathologically, the presence of discrete submucosal nodules suggestive of leiomyomas that are associated with diffuse leiomyomatosis on microscopic examination, the diffuse proliferation of smooth muscle cells seen to infiltrate between the normal skeletal muscle bundles, especially in the upper and middle part of the esophagus, and involvement of the cardia help to differentiate diffuse leiomyomatosis from esophageal hypertrophy due to achalasia cardia. These features were seen in our case.

\section{CONCLUSIONS}

Leiomyomatosis should be considered as a cause of pseudoachalasia in patients with symptoms suggestive of achalasia and atypical barium swallow findings. Attempts should be made to confirm the diagnosis preoperatively, using CT and/or EUS. Esophagectomy is the treatment of choice.

COMPETING INTERESTS: The authors declare that they have no competing interests.

ACKNOWLEDGEMENT: Written consent was obtained from the patient for publication of this paper.

AUTHORS' CONTRIBUTIONS: SR and SS were the operating team and drafted the manuscript; RG was the pathologist; TKC was the chief surgeon and critically revised the manuscript; and all authors read and approved the final manuscript.

presentation in a father and his 2 daughters. J Pediatr Surg 2005;40:e29-32.

7. Hizawa K, Esaki M, Iwai K, et al. EUS in the diagnosis of diffuse esophageal leiomyomatosis. Gastrointest Endosc 2002;56:764-6.

8. Thomas LA, Balaratnam N, Richards DG, Duane PD. Diffuse esophageal leiomyomatosis: Another cause of pseudoachalasia. Dis Esophagus 2000;13:165-8.

9. Levine MS, Buck JL, Pantongrag-Brown L, Buetow PC, Lowry MA, Sobin LH. Esophageal leiomyomatosis. Radiology 1996;199:533-6.

10. Levine MS. Benign tumors of the esophagus: Radiologic evaluation. Semin Thorac Cardiovasc Surg 2003;15:9-19.

11. Hirschl RB, Yardeni D, Oldham K, et al. Gastric transposition for esophageal replacement in children: Experience with 41 consecutive cases with special emphasis on esophageal atresia. Ann Surg 2002;236:531-41. 


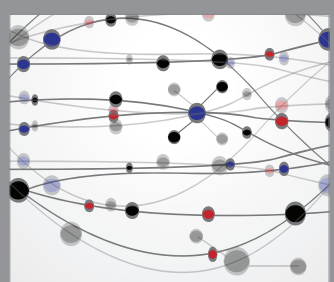

The Scientific World Journal
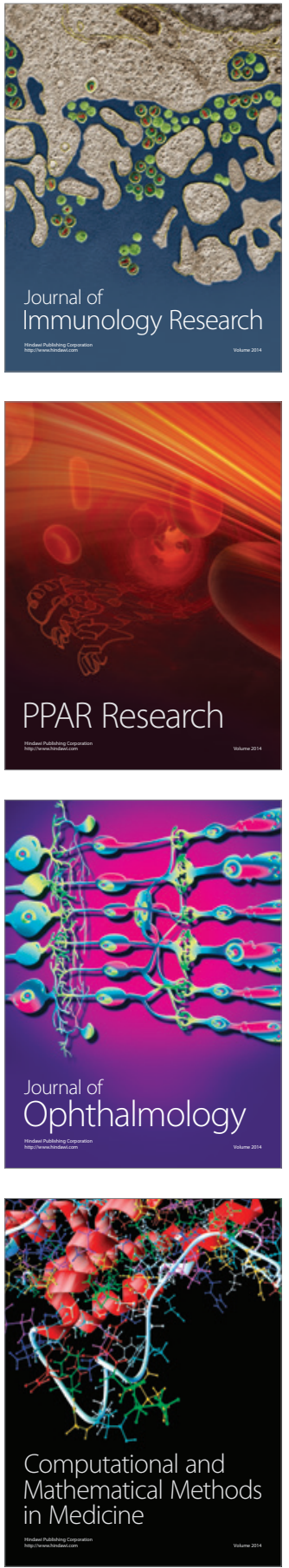

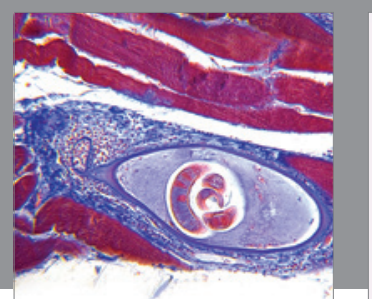

Gastroenterology Research and Practice

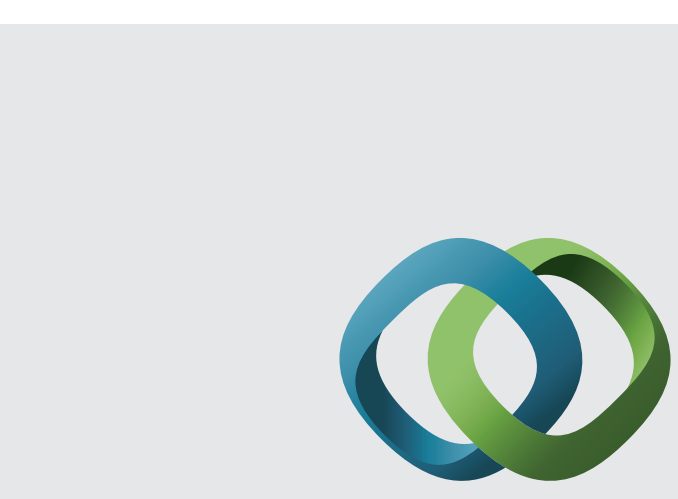

\section{Hindawi}

Submit your manuscripts at

http://www.hindawi.com
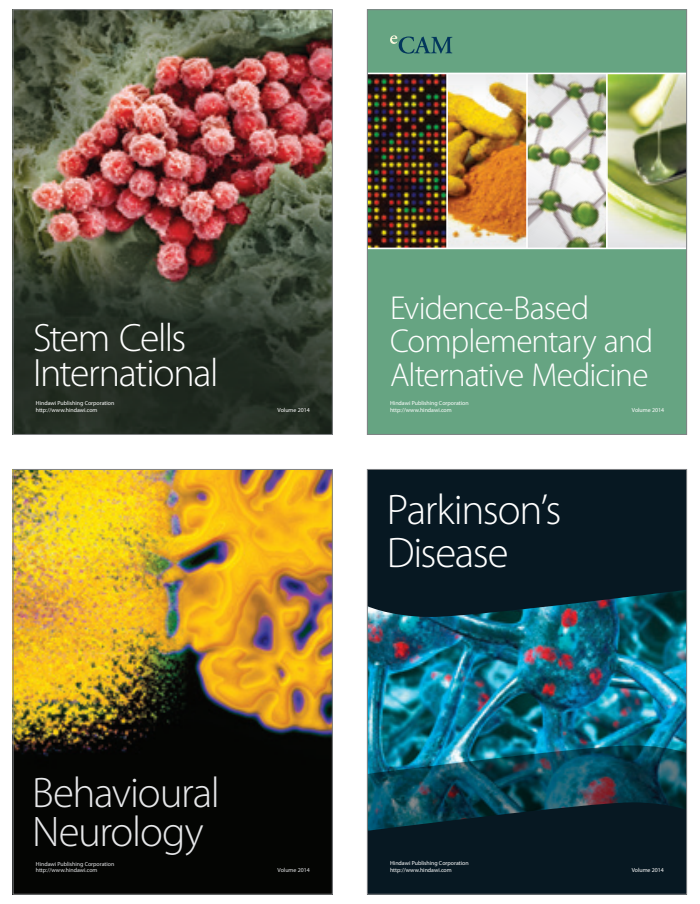
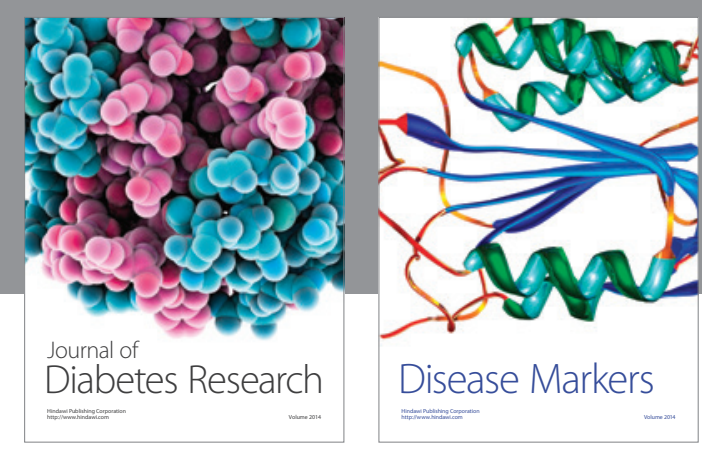

Disease Markers
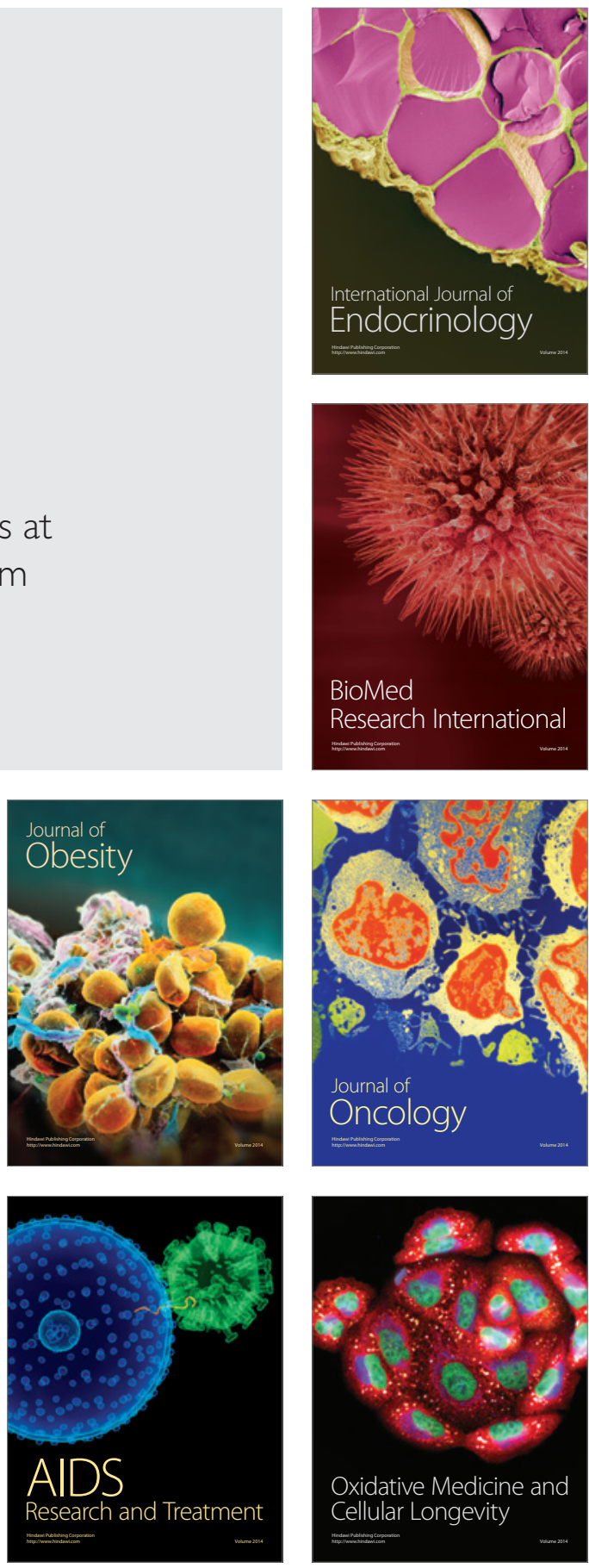